and if mucosa became sensitised IgA antibodies might be formed and inactivate the insulin. Hence the recent availability of human insulin, produced by DNA-recombinant techniques, ${ }^{9}$ appears to be more promising than porcine insulin.

We thank the healthy subjects and diabetic patients who volunteered for this study. We also acknowledge Hoechst Foundation for the generous supply of crystalline insulin and sodium glycocholate.

\author{
References \\ ${ }^{1}$ Crane CW, Path MC, Luntz GRW. Absorption of insulin from the \\ human intestine. Diabetes 1968;17:625-7. \\ ' Engel RH, Riggi SJ, Fahrenbach HJ. Insulin: intestinal absorption as \\ water-in-oil-in-water emulsions. Nature 1968;219:856-7.
}

${ }^{3}$ Leaf A, Coggins CH. The neurohypophysis. In: Williams RH, ed. Textbook of endocrinology. 5th ed. Philadelphia: W B Saunders, 1974:80-94.

- Fink G, Gennser G, Liedholm P, Thorell J, Mulder J. Comparison of plasma levels of luteinizing hormone releasing hormone in men after intravenous or intranasal administration. $\mathcal{F}$ Endocrinol $1974 ; 63: 351-60$.

${ }^{5}$ Hirai S, Ikenaga T, Matsuzama T. Nasal absorption of insulin in dogs. Diabetes $1978 ; 27: 296-9$.

${ }^{6}$ Hales CN, Randle PJ. Immunoassay of insulin with insulin-antibody precipitate. Biochem $\mathcal{F} 1963 ; 88: 137-46$.

7 Heding LG. Radioimmunological determination of human C-peptide in serum. Diabetologia 1975;11:541-8.

${ }^{8}$ Fogt EJ, Dodd LM, Jenning EM, Clemens AH. Development and evaluation of a glucose-analyzer for a glucose-controlled insulin-infusion system (Biostator R). Clin Chem 1978;24:1366-72.

${ }^{9}$ Keen H, Pickup JC, Bilous RW, et al. Human insulin produced by recombinant DNA technology: safety and hypoglycaemic potency in healthy men. Lancet $1980 ;$ ii:398-401.

(Accepted 14 September 1981)

\title{
Failure of hyposensitisation in treatment of children with grass-pollen asthma
}

\author{
D J HILL, C S HOSKING, M J SHELTON, M W TURNER
}

\begin{abstract}
Twenty asthmatic children with laboratory proved bronchial reactivity to rye-grass pollen were studied over two consecutive grass-pollen seasons. In the first year 11 patients received preseasonal hyposensitisation treatment with an aqueous rye extract and nine received placebo injections. No treatment was given in the second year. Patients in both the active-treatment and placebo groupsshowed a pronounced clinical deterioration in their asthma during both pollen seasons. Serum concentrations of IgG-specific antibodies to the rye allergen before treatment were similar in both groups, but after immunotherapy and before the pollen season in the first year these antibody concentrations were raised significantly in the treated group $(p<0.005)$ : by the middle of the pollen season the difference was no longer significant. IgE-specific antibodies showed a similar but nonsignificant pattern of response.

We found no evidence that limited hyposensitisation with a pollen extract is of any clinical benefit in seasonal asthma despite evidence of an immunological response.
\end{abstract}

\section{Introduction}

Hyposensitisation is effective in allergic rhinitis due to grasspollen sensitivity, ${ }^{1-3}$ and a favourable response to this treatment has been associated with increased production of so-called blocking antibodies and IgE antibodies specific for grass pollen. ${ }^{12}$ The value of hyposensitisation in asthma is less clear, though there is some evidence of its value. ${ }^{4}$ Studies which have

Royal Children's Hospital, Melbourne, Victoria 3052, Australia D J HILL, MB, FRACP, consultant allergist

C S HOSKING, FRACP, FRCPA, director, department of immunology M J SHELTON, MSC, immunologist

Department of Immunology, Institute of Child Health, London WC1N IEH

M W TURNER, PHD, MRCPATH, reader in immunochemistry failed to show a beneficial effect of hyposensitisation in asthma have been criticised on the grounds that bronchial reactivity to the allergen had not been demonstrated, the dose of allergen was inappropriate, or evidence of any immunological response to the treatment was lacking.

We have reported a deterioration in the asthma of children with grass-pollen bronchial reactivity during the grass-pollen season $^{6}$ and now report on the value of hyposensitisation to rye-grass pollen in such children. We evaluated the efficacy of treatment by assessing clinical symptoms, drug usage, and specific IgE and IgG antibody responses.

\section{Subjects and methods}

We studied 13 boys and seven girls aged 9 to 14 years (median 11 years). They were selected as follows. A questionnaire was distributed at random to 1000 children in the Melbourne metropolitan area. A total of 600 responses were received, from which 58 children with a history of wheeze consistent with asthma were selected. They were admitted to hospital and subjected to bronchial provocation tests with allergens. The 20 children included here gave immediate reactions to an aqueous rye-pollen extract, 11 of them had a further reaction at six to eight hours. All patients gave a positive reaction to a skin-prick test with rye grass, and 18 were also sensitive to Dermatophagoides pteronyssinus and other antigens.

All 20 children had had a history of recurrent wheeze for at least three years, and 11 had wheezed since early childhood. In the year before the study all had suffered at least four episodes of wheezing for at least $\mathbf{7 2}$ hours both during and outside the grass pollen season; 10 patients had had more than seven episodes. All patients were under the care of their family doctor and nine used prophylactic asthma medication throughout the study (eight inhaled sodium cromoglycate and one beclomethasone dipropionate). The one patient using beclomethasone and three of those inhaling cromoglycate also inhaled nebulised bronchodilator solutions regularly. All other patients had used oral or aerosol bronchodilators intermittently in the year before the study and continued to use these medications throughout.

The purpose of the study was fully explained to both the children and their parents and informed consent obtained.

Four months before the trial the children were admitted to the Royal Children's Hospital, Melbourne, for bronchial provocation tests with rye-grass pollen extract and blood sampling. They were then allocated at random to receive either active treatment $(n=11)$ or a placebo $(n=9)$. Those given active treatment underwent rush 
desensitisation. Four months before the grass-pollen season (June) they were admitted to hospital and had repeated subcutaneous injections with increasing concentrations of aqueous rye-grass extract at intervals of two to three hours until the maximum dose of allergen which could be tolerated was reached. This dose, which ranged from 75 to 1000 protein nitrogen units was repeated every two weeks until the start of the season and then every four weeks until the season finished. In one patient, stabilised with a maximal dose of allergen, an anaphylactic reaction occurred and subsequent injections were given with a lower dose of allergen.

The placebo group received injections containing 1 protein nitrogen unit of rye-pollen extract every month. All injections were stopped at the end of the grass-pollen season in the first year. No injections were given to either group in the second year of the study. A single batch of aqueoús rye-grass pollen extract was used throughout.

\section{CLINICAL INVESTIGATIONS}

The children attended the outpatient clinic three times each yearnamely, before, during, and after the grass-pollen seasons. All were assessed clinically, and most gave a blood sample. Serum samples were stored at $-20^{\circ} \mathrm{C}$. At each visit details of symptoms and medical

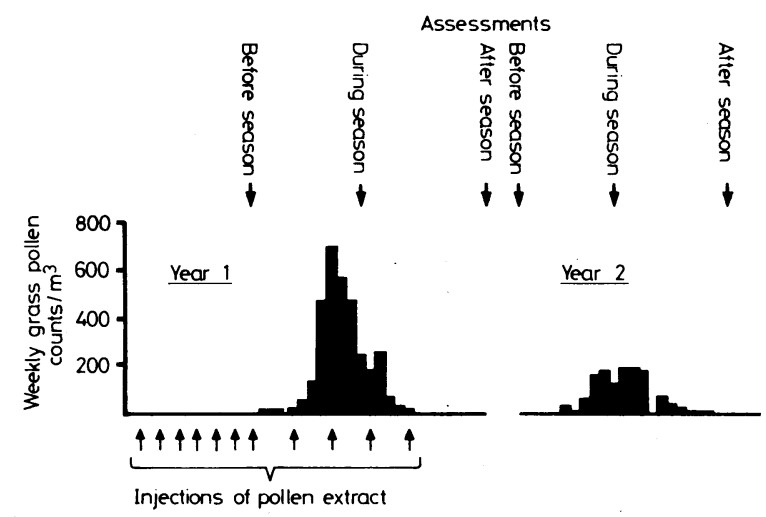

FIG 1 -Weekly pollen counts during two pollen seasons covered by study. of inhalations required each day. A total drug score was derived by adding together the individual scores of each medication. No child required oral steroids during the trial.

\section{METHODS}

Daily pollen counts were obtained during the study with a Burkhardt spore trap, situated on the roof of a building $42 \mathrm{~m}$ above the ground in the centre of Melbourne. The technique of sampling and method of measuring daily grass-pollen counts have been described. ${ }^{6}$ In this study daily grass-pollen counts were added together and reported as weekly counts.

IgE antibodies to rye-grass pollen extract were measured by the radioallergosorbent test $^{7}$ and results expressed in arbitrary radioallergosorbent test units (units $/ \mathrm{ml}$ ), as recommended by Pharmacia Diagnostics, AB, Sweden.

IgG antibodies to the group I protein of rye-grass pollen were measured by a double-antibody-binding procedure essentially as described by Platts-Mills et al. ${ }^{8}$ All sera were assayed either in duplicate or triplicate to give a mean value, and binding activity was expressed in units calibrated against a standard serum.

Statistical analyses were performed with a Hewlett Packard 3000 computer at the Royal Children's Hospital using the Statistical Package for the Social Sciences (SPSS) program. Non-parametric tests were used throughout, and the null hypothesis was rejected when $\mathrm{p}<0.05$

\section{Results}

Figure 1 shows the basic design of the study together with the weekly grass-pollen counts during each season. Counts were lower and peaked later in the second year, but in both years the midpoint assessments coincided with times of high counts.

Table I shows data for the clinical and immunological variables studied in all patients regardless of treatment. Though both the cumulative clinical and drug scores increased during and fell after the pollen season in both years, these changes did not always reach statistical significance. Similarly, concentrations of specific IgE and IgG antibodies to rye pollen rose during and fell after both pollen seasons, though at the time of the post-seasonal assessment these concentrations were higher than in the preseason samples.

When the data were analysed according to treatment group the

TABLE I-Seasonal changes in clinical and immunological variables of rye-sensitive asthmatic children in years 1 and 2 of study (two-tailed significance values by Wilcoxon signed rank tests)

\begin{tabular}{|c|c|c|c|c|c|c|}
\hline & \multicolumn{2}{|c|}{ Before season $v$ during season } & \multicolumn{2}{|c|}{ During season $v$ after season } & \multicolumn{2}{|c|}{ Before season $v$ after season } \\
\hline $\begin{array}{l}\text { Clinical score } \\
\text { Drug score } \\
\text { IgE anti-rye concentration } \\
\text { IgG anti-rye concentration }\end{array}$ & $\begin{array}{l}\text { Increase } \\
\text { Increase } \\
\text { Increase } \\
\text { Increase }\end{array}$ & $\begin{array}{l}<0.05 \\
\text { NS } \\
\text { N.020 } \\
\text { NS }\end{array}$ & $\begin{array}{l}\text { Decrease } \\
\text { Decrease } \\
\text { Decrease } \\
\text { Decrease }\end{array}$ & $\begin{array}{l}0.001 \\
0.005 \\
0.001 \\
\text { NS }\end{array}$ & $\begin{array}{l}\text { Decrease } \\
\text { Decrease } \\
\text { Increase } \\
\text { Increase }\end{array}$ & $\begin{array}{l}\text { NS } \\
\text { NS } \\
<0 \cdot 01 \\
\text { NS }\end{array}$ \\
\hline
\end{tabular}

*Direction of change observed in most patients. NS $=$ Not significant

treatment in the preceding four weeks were recorded for analysis at the completion of the study.

A symptom score was calculated from: (a) the frequency of wheezing, graded 0-3 (no wheeze (0), up to two episodes (1), four episodes (2), continuous wheeze (3)); (b) the number of days absent from school due to asthma; and (c) parental assessment of severity of asthma, assessed by one parent on a scale from 0 to $10(0$, no asthma; 10 , severe asthma). A final symptom score was obtained by summation of $(a),(b)$, and $(c)$.

Sodium cromoglycate, theophylline, and sympathomimetic medication were scored according to the number of times they had been administered daily and beclomethasone dipropionate by the number seasonal influence on the cumulative clinical and drug scores of the patients was still apparent (table II).

In the first year asthma, as reflected by the symptom and drug scores, was significantly worse in the hyposensitised patients during the pollen season than before the season (clinical scores $\mathrm{p}<0.05$; drug scores $\mathrm{p}<0.05$; Wilcoxon signed rank test). Similar trends were observed in the placebo group but did not attain significance. After the pollen season both groups improved clinically, but again this was significant only in the hyposensitised patients (clinical scores $p<0.01$; drug scores $p<0.05$; Wilcoxon signed rank test). In the second year similar fluctuations again occurred but reached significance for the change in clinical score of the placebo group only between the middle 
TABLE II-Median symptom and drug scores in each treatment group before, during, and after grass-pollen seasons

\begin{tabular}{|c|c|c|c|c|c|c|}
\hline & \multicolumn{3}{|c|}{ Year 1} & \multicolumn{3}{|c|}{ Year 2} \\
\hline & $\begin{array}{l}\text { Before } \\
\text { season }\end{array}$ & $\begin{array}{l}\text { During } \\
\text { season }\end{array}$ & $\begin{array}{c}\text { After } \\
\text { season }\end{array}$ & $\begin{array}{l}\text { Before } \\
\text { season }\end{array}$ & $\begin{array}{c}\text { During } \\
\text { season }\end{array}$ & $\begin{array}{l}\text { After } \\
\text { season }\end{array}$ \\
\hline $\begin{array}{l}\text { Patients given active treatment } \\
\text { Patients given placebo }\end{array}$ & $\begin{array}{c}\text { Sympt } \\
3 \\
4 \\
\text { Dru }\end{array}$ & $\begin{array}{c}\text { tom score } \\
7 \\
5 \\
g \text { score }\end{array}$ & $\begin{array}{l}3 \\
1\end{array}$ & $\begin{array}{l}3 \\
2\end{array}$ & $\begin{array}{l}3 \\
5\end{array}$ & $\begin{array}{l}2 \\
1\end{array}$ \\
\hline $\begin{array}{l}\text { Patients given active treatment } \\
\text { Patients given placebo }\end{array}$ & $\begin{array}{l}4 \\
1\end{array}$ & $\begin{array}{l}5 \\
2\end{array}$ & $\begin{array}{l}2 \\
1\end{array}$ & $\begin{array}{l}4 \\
1\end{array}$ & $\begin{array}{l}4 \\
2\end{array}$ & $\begin{array}{l}3 \\
2\end{array}$ \\
\hline
\end{tabular}

and end of the season. Figure 2 gives the median concentrations of specific IgG and IgE antibodies to rye in the two treatment groups. Before hyposensitisation treatment was begun the median values for the two groups were closely similar. After hyposensitisation treatment, however, the concentrations of both IgG and IgE antibodies to rye were clearly boosted in the active-treatment group compared with the placebo-treated group. The IgG antibody concentrations were significantly different between the two groups before the season in year 1 ( $p<0.005$; Mann-Whitney $U$ test) but failed to attain significance midseason $(0.05<p<0.10 ;$ Mann-Whitney $U$ test $)$. The concentrations of specific IgE antibodies in the two groups were not significantly different at any time during the first year, and in the second year neither IgG nor IgE antibody concentrations differed between the two groups.
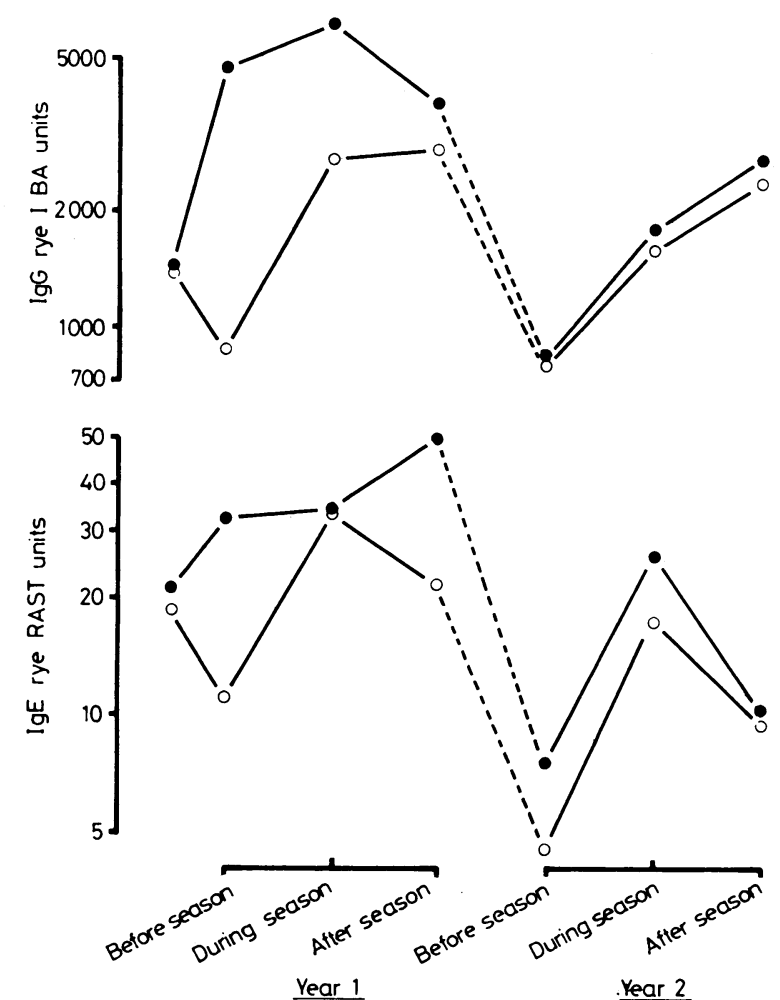

FIG 2-Median IgG and IgE rye-specific antibody concentrations for patients receiving active hyposensitisation treatment $(\bullet)$ or placebo injections (O) before, during, and after grass-pollen season each year. (IgE rye-specific antibody concentrations expressed in arbitrary radioallergosorbent test (RAST) units, and concentrations of IgG antibodies to group I protein of rye-grass pollen expressed in binding activity (BA) units calibrated against standard serum. See text.)

When the clinical and immunological data obtained in the two years of the study were compared for both treatment groups there were no significant clinical differences at any time. The IgG antibody concentrations of the active-treatment group were significantly higher in the first year than in the second, both before $(p<0.05)$ and during $(p<0.02)$ the pollen season.

\section{Discussion}

In this small study we were unable to detect any beneficial influence on the clinical course of childhood asthma after hyposensitisation treatment with an aqueous rye-grass pollen preparation. All the patients had proved bronchial sensitivity to rye-grass pollen and most, regardless of which treatment they received, showed a deterioration in their asthma during the ryepollen season. Despite convincing in-vitro evidence that patients given hyposensitisation treatment developed increased concentrations of both specific IgG and IgE anti-rye antibodies compared with the patients given placebo injections, the natural seasonal exposure to the rye allergen appeared to override these changes.

Aas $^{4}$ and Warner et $a l^{5}$ showed hyposensitisation to benefit children with asthma and proved bronchial reactivity to either house dust or $D$ pteronyssinus allergens. Both studies reported clinical benefit and improved bronchial tolerance to the allergen. We could not compare either of these studies with the present investigation. Mite antigens are probably the most potent allergen in childhood asthma, ${ }^{9-11}$ and though our patients had positive bronchial reactivity to rye-grass pollen, most of them were also sensitised to $D$ pteronyssinus, as judged by skin-prick tests and serum IgE antibody measurements. All, however, showed a pronounced deterioration of their asthma in the pollen season, though from results of studies ${ }^{1-3}$ on hyposensitisation in patients with seasonal rhinitis we had expected some clinical improvement from hyposensitisation treatment.

To try to overcome the problems associated with some hyposensitisation trials we included in our trial only patients with established bronchial reactivity; treatment and placebo groups were matched for age and clinical severity; and the hyposensitised patients received the maximal dose of allergen which could be tolerated. Furthermore, this dose of antigen was subsequently shown to induce significant concentrations of specific IgG antibody to the rye allergen. Though a beneficial "blocking" role for such antibodies is claimed to be effective in hay fever, ${ }^{212}$ recent studies suggest that these would not prevent access of allergen to sensitised mucosal mast cells. ${ }^{13}$ We found no evidence that development of IgG antibodies to grass pollen was of clinical benefit.

Though the children in this study did not benefit from hyposensitisation, we cannot discount the possibility that others with asthma due solely to grass-pollen sensitivity might benefit. Bronchial reactivity associated with such a restricted hypersensitivity is uncommon in Australian children.

We thank Ann Balloch, A McAskill, J W Turner, and Antoinette Williams for skilled technical help. Pollen counts were performed by P West, I Smart, R B Knox, and M Toohey. The rye I antigen was kindly provided by Dr D Marsh. We thank Dr T A E Platts-Mills for providing a calibrated standard sera for the rye binding assays and for helpful discussions. The aqueous rye-grass pollen extract was donated by Commonwealth Serum Laboratories (Parkville, Australia). The generous financial help of the Royal Children's Hospital pathology department, the King Edward's Hospital Fund for London, Beecham Pharmaceutical (Aust), and Pharmacia Ltd is gratefully acknowledged. DJH is a recipient of a National Health and Medical Research Council (Aust) applied health science fellowship ini allergy.

Reprint requests should be addressed to: Dr D J Hill, Royal Children's Hospital, Flemington Road, Parkville, Victoria 3052, Australia.

\section{References}

${ }^{1}$ Foucard T, Johannson SGO. Allergy specific IgE and IgG antibodies in pollen allergic children given immunotherapy for 2-6 years. Clin Allergy $1978 ; 8: 249-57$.

2 Sadan N, Rhyne MB, Mellits ED, Goldstein EO, Levy DA, Lichtenstein LM. Immunotherapy of pollinosis in children. $N$ Engl f Med 1969; 280:623-7.

${ }^{3}$ Frankland AW, Augustin R. Prophylaxis of summer hay fever and asthma. 
Controlled trial comparing crude grass pollen extracts with isolated main pollen component. Lancet $1954 ; \mathrm{i}: 1055-7$.

- Aas K. Hyposensitisation in house dust allergy asthma. Acta Paediatr Scand $1971 ; 60: 264-8$.

5 Warner JO, Price JF, Soothill JF, Hey EN. Controlled trial of hyposensitisation to Dermatophagoides pteronyssinus in children with asthma. Lancet 1978;ii:912-5.

6 Hill DJ, Smart I, Knox RB. Childhood asthma and grass pollen aerobiology in Melbourne. Med f Aust 1979;i:426-9.

7 Wide L, Bennich H, Johannson SGO. Diagnosis of allergy by an in-vitro test for allergen antibodies. Lancet 1968 ;ii:1105-7.

${ }^{8}$ Platts-Mills TAE, Snajdr MI, Ishizaka K, Frankland AW. Measurement of IgE antibody by an antigen-binding assay; correlation with $\mathrm{PK}$ activity and IgG and IgA antibodies to allergens. $\mathcal{F}$ Immunol 1978;4: 1201-10.
9 Sarsfield KJ. Role of house dust mite in childhood asthma. Arch Dis Child $1974 ; 49: 711-5$.

10 Warner JO, Price JF. House mite sensitivity in childhood asthma. Arch Dis Child 1978;53:710-3.

11 Smith JM. Skin tests and atopic allergy in children. Clin Allergy 1973;3: 269-75.

12 Lichtenstein LM, Ishizaka K, Norman PS, Sobotka AK, Hill BM. IgE antibody measurement in ragweed hay fever. Relationship to clinical severity and the results of immunotherapy. F Clin Invest 1973;52: 1268-75.

13 Chapman MD, Platts-Mills TAE, Gabriel M, et al. Antibody response following prolonged hyposensitisation with Dermatophagoides pteronyssinus extract. Int Arch Allergy Appl Immunol 1980;61:431-40.

(Accepted 21 October 1981)

\section{SHORT REPORTS}

\section{Successful emergency transoesophageal cardiac pacing with subsequent endoscopy}

Transoesophageal cardiac pacing was described in $1969 .^{1}$ Since the introduction of temporary transvenous pacing, however, it has not been used routinely in clinical practice. The recent introduction of a specially designed flexible electrode and pulse amplifier has allowed the technique to be used rapidly in asystolic patients before inserting an intracardiac pacemaker. The equipment and technique have been described. ${ }^{2}$

The condition of the oesophagus using earlier equipment was assessed in necropsy studies on patients and dogs. ${ }^{13}$ We can find no record of the endoscopic appearances of the oesophagus after using the flexible electrode. We therefore report the successful use of transoesophageal pacing and describe the endoscopic findings both at two days and at two months.

\section{Case report}

A 71-year-old woman was admitted after feeling dizzy at home. Her general practitioner had recorded a pulse of 20 beats $/ \mathrm{min}$. She was known to have had dizzy episodes but had not lost consciousness. An electrocardiogram had shown left bundle-branch block. On admission electrocardiography showed complete heart block. While the transvenous pacing was being prepared the patient developed asystole and became unconscious. A Vygon bipolar oesophageal electrode (Oesocath No 1128-02) was inserted transnasally to its full length. The battery-powered demand pacing box and Vygon Oesocath pulse amplifier were connected, giving a $30 \mathrm{~V}$ direct current pacing impulse. Pacing blips were seen on the cardiac monitor. The electrode was then withdrawn until ventricular capture occurred; this procedure was completed in less than 30 seconds. The patient regained consciousness within minutes but complained of chest pain associated with the pacing complexes. Over the next 30 minutes transvenous pacing was established and transoesophageal pacing discontinued. She remained fully conscious and had no further arrhythmia. Oesophagogastroduodenoscopy was performed 45 hours later. No evidence of any erythema, erosions, or ulceration was found. The patient was subsequently given a permanent pacemaker. Two month later she complained of mild dyspepsia; appearances on repeat oesophagogastroduodenoscopy were again completely normal.

\section{Comment}

This is only the second report of successful resuscitation of patients in asystole by emergency pacing with the new specifically designed electrodes via the oesophagus. This case demonstrates the speed of the technique and the rapidity with which the patient may recover. Our patient experienced severe chest pain, which may have been due to oesophageal contraction stimulated by the pacing impulse. Most patients who have a cardiac arrest do so after a myocardial infarction and are thus unsuitable for invasive procedures. This was not the case with our patient. Oesophagogastroduodenoscopy showed no evidence of any damage to the oesophagus.

Our experience of this new technique is limited but it seems to be a rapid and safe method of beginning resuscitation in asystolic patients. It allows subsequent intracardiac pacing to be performed with ade- quate time for good technique. Thus, like Hale et al, ${ }^{2}$ we consider that transoesophageal pacing has a definite place in an emergency.

${ }^{1}$ Burack B, Furman S. Transoesophageal cardiac pacing. Am $\mathcal{f}$ Cardiol $1969 ; 23: 469-72$

${ }^{2}$ Hale J, Kelly AJ, Bowes RJ, Ilchyshyn A, Ellenbogen BK. Emergency transoesophageal cardiac pacing. Cardiovasc Technol 1980;22:38-9.

${ }^{3}$ Lubell DL. Cardiac pacing from the oesophagus. Am $\mathcal{f}$ Cardiol 1971 ;27: 641-4.

(Accepted 13 October 1981)

St Richard's Hospital, Chichester, Sussex

R J SHAW, BSC, MRCP, registrar (present address: Cardiac Department, St George's Hospital, London SW 17)

L H BERMAN, MRCP, locum registrar (present address: Radiology Department, Northwick Park Hospital, Harrow, Middlesex)

J M HINTON, FRCP, consultant

\section{Toxocaral and toxoplasmal antibodies in cat breeders and in Icelanders exposed to cats but not to dogs}

Surveys using the immunosorbent assay (ELISA) technique have shown that $2 \cdot 6 \%$ of healthy adults have toxocaral antibody in their plasma, indicating past or present infection. Woodruff et al ${ }^{1}$ however, found toxocaral antibody in 16 of 102 exhibitors at a large dog show. The question arises whether cat breeders and owners are similarly infected. We sought an answer to this with the co-operation of exhibitors at the 1979 Bedford and district cat club show. Epidemiological data were also obtained from examination of sera from 307 adult Icelanders. In Iceland dogs have been prohibited for 40 years to control hydatid disease but there has been no restriction on ownership of cats, of which there is a large population.

\section{Subjects, methods, and results}

Questionnaires were answered voluntarily by 67 cat breeders or owners exhibiting at the 1979 Bedford show and blood was obtained by venepuncture at the same time. Serum was separated immediately and stored at $4^{\circ} \mathrm{C}$ until examined by the ELISA technique of de Savigny et al. ${ }^{2}$ Sera obtained from healthy blood donors in Iceland were examined in the same way as those from 922 healthy adults obtained by courtesy of the Brentwood and Milton Keynes district blood transfusion services. ELISA values of 0.5 or more indicate past or current infection. The toxoplasmal antibody estimations were carried out using the dye test.

Toxocariasis-Out of the 67 cat breeders and exhibitors, only one gave a positive response to the ELISA test $(1.5 \%)$, compared with $24(2.6 \%)$ of the 922 blood donor controls. The mean age of the cat breeders and exhibitors was 38.4 years $( \pm S D 11.5)$ and that of the healthy controls 34.5 years 